\title{
Development and antitumor activity of a BCL-2 targeted single-stranded DNA oligonucleotide
}

\author{
Wendi V. Rodrigueza $\cdot$ Michael J. Woolliscroft $\cdot$ Abdul-Shukkur Ebrahim $\cdot$ Robert Forgey $\cdot$ Patrick J. McGovren \\ Gerold Endert · Andreas Wagner • Danielle Holewa • Amro Aboukameel · Richard D. Gill • Charles L. Bisgaier • \\ Richard A. Messmann · Christopher E. Whitehead · Elzbieta Izbicka $\cdot$ Robert Streeper $\cdot$ Michael C. Wick · \\ Gabriela Stiegler · C. A. Stein · David Monsma · Craig Webb · Mina P. Sooch · Steffen Panzner • \\ Ramzi Mohammad $\cdot$ Neal C. Goodwin $\cdot$ Ayad Al-Katib
}

Received: 22 November 2013 / Accepted: 23 April 2014 / Published online: 16 May 2014

(C) The Author(s) 2014. This article is published with open access at Springerlink.com

\begin{abstract}
PNT100 is a 24-base, chemically unmodified DNA oligonucleotide sequence that is complementary to a region upstream of the BCL-2 gene. Exposure of tumor cells to PNT100 results in suppression of proliferation and cell death by a process called DNA interference. PNT2258 is PNT100 that is encapsulated in protective amphoteric liposomes developed to efficiently encapsulate the PNT100 oligonucleotide, provide enhanced serum stability, optimized pharmacokinetic properties and antitumor activity of the nanoparticle both in vivo and in vitro. PNT2258 demonstrates broad antitumor activity against BCL-2-driven WSU-DLCL2 lymphoma, highly resistant A375 melanoma, PC-3 prostate, and Daudi-Burkitt's lymphoma xenografts. The sequence specificity of PNT100 was demonstrated against three control sequences (scrambled, mismatched, and reverse complement) all encapsulated in a lipid formulation with identical particle characteristics, and control sequences did not demonstrate antiproliferative activity in
\end{abstract}

Electronic supplementary material The online version of this article (doi:10.1007/s00280-014-2476-y) contains supplementary material, which is available to authorized users.

W. V. Rodrigueza $(\bowtie) \cdot$ M. J. Woolliscroft $\cdot$ R. Forgey

P. J. McGovren · D. Holewa · R. D. Gill · C. L. Bisgaier ·

R. A. Messmann · C. E. Whitehead · M. P. Sooch ·

N. C. Goodwin

ProNAi Therapeutics, Inc., Plymouth, MI, USA

e-mail:wrodrigueza@pronai.com

A.-S. Ebrahim · A. Aboukameel · R. Mohammad · A. Al-Katib

Wayne State University, Detroit, MI, USA

G. Endert · S. Panzner

Novosom AG, Halle, Germany

A. Wagner · G. Stiegler

Polymun Scientific GmbH, Klosterneuburg, Austria vivo or in vitro. PNT2258 is currently undergoing clinical testing to evaluate safety and antitumor activity in patients with recurrent or refractory non-Hodgkin's lymphoma and additional studies are planned.

Keywords PNT2258 $\cdot \mathrm{DNAi}^{\circledR} \cdot \mathrm{BCL}-2 \cdot$ Liposomes Anticancer agent $\cdot$ Deoxyribonucleic acid interference

\section{Introduction}

BCL-2, a member of the antiapoptotic protein family, plays a key and central role in preventing cell death, a defining characteristic of malignant cells [1]. BCL-2 confers an antideath phenotype and its overexpression contributes to the genesis of hematopoietic and lymphatic cancers [2-6]. Aberrant BCL-2 expression is driven by $t(14 ; 18)$ chromosomal rearrangement of the BCL-2 gene in many follicular (FL) and diffuse large B cell (DLBCL) lymphomas [3-6]. In chronic lymphocytic leukemia, impaired degradation of BCL-2 mRNA is linked to nucleolin and/or microRNA

\author{
E. Izbicka $\cdot$ R. Streeper \\ BTNS, LLC, San Antonio, TX, USA \\ M. C. Wick \\ South Texas Accelerated Research Therapeutics (START), LLC, \\ San Antonio, TX, USA \\ C. A. Stein \\ Montefiore Medical Center and the Albert Einstein College \\ of Medicine, New York, NY, USA \\ D. Monsma $\cdot$ C. Webb \\ Van Andel Research Institute, Grand Rapids, MI, USA
}


expression, resulting in continuous production of BCL-2 protein and the subsequent survival of leukemic cells $[7$, 8]. In cancers of the breast, skin, prostate, sarcomas, and lung, BCL-2 is implicated in the development of chemoresistance [9]. Given its biological importance, BCL-2 is a desirable target for therapeutic development. Numerous approaches have been reported to block or modulate the production of BCL-2 at the DNA level (e.g., retinoids and histone deacetylase inhibitors), at the RNA level (targeted antisense oligonucleotides, siRNA or miRNA), or the protein level (e.g., pan inhibitors of BH3 family members of BCL-2, or recently the specific BCL-2 inhibitor, ABT-199) reviewed in [10].

There is an emerging understanding that $\mathrm{CpG}$ islands surround mammalian cell promoter regions and that these non-methylated regions contribute to gene regulation [11, 12]. The recognition that these genomic regions are DNAse I-hypersensitive enabled the discovery of cis-regulatory elements that act as transcription factors, enhancers, silencers, repressors, or control regions, which regulate gene expression [13-15]. Additionally, higher-order secondary structures (quadruplexes, cruciforms, or I-motifs) that surround the promoter regions of oncogenes may also serve as cis-regulatory domains to modulate transcription [16, 17]. It has been demonstrated that exposing cells to short DNA sequences containing these motifs reduced mRNA and protein levels $[18,19]$. Others have recognized the importance of regulatory regions specific for BCL-2 [20-23]. Young and Korsmeyer demonstrated that a series of 20 base deletions between the $\mathrm{P} 1$ and $\mathrm{P} 2$ promoter of BCL-2 decreased transcription. Miyashita et al. reported that p53-dependent regions upstream of the BCL-2 gene act as negative regulatory elements, and Duan et al. showed long-range regulatory effects on BCL-2 transcription by enhancers in the IgH 3' region. The observations support the hypotheses that these regulatory regions may be favorable therapeutic targets for hybridization due to the accessible chromatin state during oncogene up-regulation and transcription.

We describe a novel approach to blocking transcription termed DNA interference (DNAi $\left.{ }^{\circledR}\right)$. DNAi therapeutic candidates are a new class of nucleic acid-based drugs. They are single-stranded sequences of unmodified phosphodiester DNA having lengths of 20-34 bases. These sequences are designed to be complementary to non-coding, nontranscribed regions of genomic DNA upstream of gene transcription start sites. The hybridization of the DNAinterfering oligonucleotide to its targeted region results in gene modulation with phenotypic changes and a modulation of mRNA and protein levels. While DNAi against BCL-2 is described in this paper, DNAi oligonucleotides may be designed to also target other regions of the genome to modulate genes. We describe here the development of PNT2258, containing PNT100, a 24-base single-stranded
DNA oligonucleotide specific to BCL-2 encapsulated in amphoteric liposomes. The liposomes protect the oligonucleotides from nuclease degradation, facilitate cellular uptake, and enable endosomal escape to the nucleus, where the biological effects of the oligonucleotides occur [2426]. PNT2258 is currently undergoing clinical development against BCL-2-driven malignancies [27].

\section{Materials and methods}

PNT100 and control DNAi oligonucleotides

Oligonucleotides were produced by multi-step solid-phase organic synthesis involving on-column cleavage from solid support, base de-protection, followed by ion exchange (IEX) purification, ultrafiltration/diafiltration, concentration, and freeze-drying. The PNT100 and controls include: PNT100, 5'-CACGCACGCGCATCCCCGCCCGTG-3'; methylated PNT100, 5'-CAXGCAXGXGCATCCCXGCC XGTG-3', where $\mathrm{X}$ represents a methylated cytosine base; scrambled control, 5'-CGGCGTGCACCCCACCCACGCC GT-3'; reverse complement control, 5'-CACGGGCGGGGA TGCGCGTGCGTG- $3^{\prime}$, which is the reverse sequence of PNT100 and is $100 \%$ homologous with the coding strand; mismatched control, 5'-CACGCACGCGCATCCTTGCCC GTG-3' or 5'-CACGCACGCGCATCCTTGCCCATG-3'; randomer, $5^{\prime}$-NNNNNNNNNNNNNNNNNNNNNNNN-3', where N represents a wobble; PNT100cy 5'-CACGCGCGCG CATCCCCGCCCGTG- $3^{\prime}$. Oligonucleotides were purchased from TriLink, Dow, Sigma, or NITTO DENKO Avecia.

Lipids and transfection agents

NeoPhectin AT containing the cationic cardiolipin 1, 3-Bis-(1,2-bis-tetradecyloxy-propyl-3-dimethylethoxyammoniumbromide)-propane 2-ol was purchased from NeoPharm (Waukegan, IL). 1-Palmitoyl-2-oleoyl-sn-glycero-3 phosphocholine (POPC) and 1,2-dioleoyl-sn-glycero3-phosphoethanolamine (DOPE) were purchased from Lipoid GmbH or Avanti Polar Lipids. Cholesteryl hemisuccinate (CHEMS) and cholesteryl-4-[[2-(4-morpholinyl) ethyl]amino]-4-oxobutanoate (MOCHOL) were produced by Merck \& Cie (Shaffhuasen, Switzerland).

Preparation of encapsulated oligonucleotides and PNT2258

During preliminary screening, oligonucleotides were encapsulated in a variety of liposome compositions, including the cationic NeoPhectin AT system and into various amphoteric liposomes denoted as SMARTICLES ${ }^{\circledR}$ (from Novosom AG, now Marina Biotech). While NeoPhectin 
spontaneously forms liposomes upon mixing with oligonucleotides, the other lipids that generate the amphoteric liposomes were mixed in ethanol and combined with an acidified ( $\mathrm{pH} 4)$ aqueous solution of each oligonucleotide tested. The mixing process with the latter results in encapsulation in a $30 \%$ ethanol suspension followed by dilution in an excess of phosphate-buffered saline with simultaneous neutralization to pH 7.5 [26, 28, 29]. For PNT2258, a cross-flow injection technique was utilized to enable continuous mixing of the lipid ethanolic solution with aqueous PNT100 to encapsulate PNT100 in liposomes followed by an immediate $\mathrm{pH}$ shift to neutralize the mixture. Ethanol was removed by dialysis or diafiltration to exchange saline with sucrose (phosphate-buffered sucrose), followed by sterile filtration and filling into glass vials.

Characterization of the physicochemical properties of formulation solutions and dosing solutions of oligonucleotides

OD260-derived concentrations, representing total oligonucleotide content, were used to compare encapsulated oligonucleotide dosing solutions used for animal studies with PNT100, control oligonucleotides, and prototype PNT2258 formulations. Standard curves with each oligonucleotide were used along with spectral scans to confirm the OD260 contribution resulted from the oligonucleotides and not the liposome/lipid nanoparticles. The percent unencapsulated oligonucleotide was determined by OD260 following ultrafiltration using Centrisart $100 \mathrm{~K}$ cutoff membranes. Where indicated, the PNT2258 concentrations were reported as PNT100 content after correcting for purity as determined by ion exchange (IEX) chromatography. Reverse-phase HPLC was used to quantify lipids in the nanoparticles. Particle diameters and zeta potentials were determined by dynamic light scattering using a Malvern Nano ZS (Malvern, PA).

\section{Cell culture and treatment with DNAi}

Cell lines were maintained in suspension or monolayer cultures in media supplemented with $10 \%$ fetal bovine serum (FBS). Breast (MDA-MB-231, BT-474, and T47D), melanoma (A375 and M14), prostate PC-3, lymphoma (DaudiBurkitt's, SU-DHL-6, and Pfeiffer), and mouse mammary NMuMG lines were purchased from ATCC ${ }^{\circledR}$. WSU-DLCL2 and WSU-FSCCL lines were purchased from DSMZ GmbH (Germany) or provided by Ramzi Mohammad of Wayne State University. The cell lines were authenticated by the providers and were maintained under the recommended conditions for propagation and experimental use.

Unless otherwise noted, cell exposure studies utilized methylated oligonucleotides without formulation. For adherent lines, cells were seeded in 6- or 24- well plates or
T-25 flasks (Corning Life Sciences) at $2.0 \times 10^{5}$ cells per flask in $5 \mathrm{~mL}$ media. One day after passage, the medium was replaced with fresh media containing the test oligonucleotides. Cultures were incubated at $37{ }^{\circ} \mathrm{C}$ in a humidified atmosphere of $5 \% \mathrm{CO}_{2}$. Cells were washed with $1 \times \mathrm{PBS}$ and incubated with $0.25-1 \%$ trypsin and $0.02 \%$ EDTA to disperse the cells. The number of living and dead cells was assessed following $0.1 \%$ trypan blue exposure, with the percentage of inhibition reported as a percent of live cells present in saline-treated controls. The effects of treatment on proliferation were assessed using MTT assay with 2,500 cells per well seeded in 96-well plates. Suspended cells were grown in 24-well plates and treated as described above. For PC-3 exposure studies, oligonucleotides were formulated with NeoPhectin. Typically, cells were exposed for $30 \mathrm{~min}$ or $6 \mathrm{~h}$, washed, then the effects of treatment on proliferation were assess by CellTiter-Glo ${ }^{\circledR}$ (Promega) $48 \mathrm{~h}$ post-treatment or BCL-2 and GAPDH expression was measured by qPCR.

Pharmacokinetics, pharmacology, tissue distribution, and xenograft studies

\section{Pharmacokinetic studies and xenograft animal studies}

PNT2258 and its prototypes were evaluated as single agents or in combination in four different human tumor xenograft model systems. Two of the models were nonHodgkin's lymphoma models (WSU-DLCL2 (a diffuse large B-cell) and Daudi-Burkitt's). The other xenograft models included A375 melanoma and the PC-3 hormone refractory prostate carcinoma. For WSU-DLCL2, female ICR SCID mice (Taconic) or female C.B-17 SCID mice were implanted subcutaneously with donor WSU-DLCL2 xenograft fragments in their flanks. A parallel set of WSUDLCL2 xenograft mice were also used for tissue distribution studies. For Daudi-Burkitt's, female C.B-17 SCID mice were implanted subcutaneously with $1 \times 10^{7}$ Daudi cells in their flanks. A parallel set of Daudi-Burkitt's xenograft mice were also used for pharmacokinetic and tissue distribution studies. For A375, female nu/nu mice were implanted subcutaneously in the flank with $1 \mathrm{~mm}^{3}$ fragments. For PC-3, male SCID/NCr mice were subcutaneously implanted with $5 \times 10^{6}$ PC-3 cells. All xenograft tumor models were conducted through contract or research collaborations at MPI Research (PC-3), South Texas Accelerated Research Therapeutics (A375 and WSU-DLCL2), Piedmont Research (Daudi and A375), Karmanos Cancer Center (WSU-DLCL2), and Van Andel Research Institute (PC-3). BALB/C mice were purchased from Charles River Labs and used for pharmacokinetic studies. Test samples were provided in a blinded manner. All protocols and procedures employed in this work were approved by each 
testing centers' Institutional Animal Care and Use Committee (IACUC).

\section{Animal monitoring, tumor measurement, and data calculation}

Upon attaining tumor volumes of $100-200 \mathrm{~mm}^{3}$, animals were randomized into treatment groups. Thereafter, clinical signs, tumor measurements, and body weights were recorded 3-5 times per week. Tumor volume was calculated using the formula $\left(l \times w^{2}\right) / 2$, where $l$ and $w$ are the length and width of the tumor, respectively. Animals were euthanized when tumor sizes reached $1,000 \mathrm{~mm}^{3}$, $2,000 \mathrm{~mm}^{3}$ or at approximately 60 days depending on the research organizations' approved protocols. Efficacy endpoints, including time to tumor endpoint, tumor growth delay, and net $\log _{10}$ cell kill, were calculated as follows using previously described methods [30]. Gross cell kill was calculated using the following formula: [T-C (days)]/ $(3.32 * \mathrm{Td})$, where $\mathrm{T}-\mathrm{C}$ is the tumor growth delay and $\mathrm{Td}$ is the tumor volume doubling time (days). Individual tumor volumes which decreased to $<50 \%$ of their volumes at treatment initiation for three consecutive measurements were considered partial regressions (PR). Individual tumor volumes that were not measurable for three consecutive measurements were considered complete regressions (CR). Complete regressions persisting until the end of the study were considered tumor-free survivors (TFS). Data and statistics were analyzed using Prism 5.0 (GraphPad; San Diego, CA) and Microsoft Excel.

\section{Plasma measurement of PNT2258 by hybridization- ligation and plasma immune markers}

Whole blood was collected in $\mathrm{K}_{2}$ EDTA-coated tubes, placed on ice, centrifuged to obtain plasma and stored at $-80{ }^{\circ} \mathrm{C}$ until analyses. Samples were treated with $10 \%$ (v/v) Tween-20 detergent and heated to $90{ }^{\circ} \mathrm{C}$ to liberate PNT100 from PNT2258 then diluted fourfold with a template probe (complementary and specific to the entire sequence of PNT100) labeled with biotin on its $3^{\prime}$-end and a 9-mer overhang to the opposing end. The solution was incubated at $37{ }^{\circ} \mathrm{C}$ for $1 \mathrm{~h}$ in NeutrAvidin-coated plates, prior to the addition of a mixture containing a digoxigeninlabel signal probe which ligates the $3^{\prime}$ terminus of PNT100 with the $5^{\prime}$ end of the ligation probe. Unbound ligation probe was washed away prior to antibody (targeting digoxigenin) addition and conjugation to alkaline phosphatase. AttoPhos ${ }^{\circledR}$ substrate was added and the reaction terminated with EDTA solution prior to fluorescent signal measurement (excitation: $435 \mathrm{~nm}$; emission: $555 \mathrm{~nm}$ ). The lower limit of quantitation (LLOQ) was $3 \mathrm{ng} / \mathrm{mL}$ using PNT2258 as a standard. Multiplex immunoassays of mouse plasma obtained from WSU-DLCL2-tumored animals $8 \mathrm{~h}$ postPNT2258 dose were assayed in triplicate per the Affymetrix Procarta Mouse 37-plex kit protocols (Fremont, CA) and visualized using a Luminex 100 IS System (Luminex Corporation, Austin, TX). Analyte concentrations were calculated from the standard curves using Bio-Plex Manager 4.1.1 (Bio-Rad Laboratories, Hercules, CA). Statistical analysis was done using Student $\mathrm{t}$ statistic; $P$ values $<0.05$ were considered significant.

\section{Pharmacodynamic sampling of tumors and PNT2258 tissue levels}

Tumors and organs were collected, snap frozen, weighed, and stored until analyses. Tissue levels of PNT2258 were assessed by two independent labs, Charles River Labs and Helix Diagnostics, using the hybridization-ligation assay described above for plasma analyses (LLOQ: $50 \mu \mathrm{g} / \mathrm{g}$ of tissue) or by capillary gel electrophoretic detection (LLOQ: $5 \mathrm{ng} / \mathrm{g}$ of tissue). PNT2258 levels in xenograft tumors were measured through direct hybridization with capture and extender probes that recognize only PNT100 amidst the total RNA extract (LLOQ 300,000 copies of PNT100). Tumor homogenates were prepared by pulverizing tumors under liquid nitrogen, followed by homogenization in 900 $\mu \mathrm{L}$ of homogenizing solution (Affymetrix) supplemented with $9 \mu \mathrm{L}$ of proteinase $\mathrm{K}(50 \mathrm{mg} / \mathrm{mL})$. The homogenates were incubated at $65{ }^{\circ} \mathrm{C}$ for $30 \mathrm{~min}$, then clarified by centrifugation, and stored at $-70{ }^{\circ} \mathrm{C}$ until analyses. Tumors excised from animals treated with PNT100 formulated with NeoPhectin, PNT100R formulated with NeoPhectin, NeoPhectin alone, or sucrose (vehicle control) were pooled into groups, dissected mechanically into single cell suspensions, and subjected to protein analysis by Western blot using antibodies (Santa Cruz Biotechnology) along with total protein quantitation by BCA assay (Pierce).

\section{Results}

Demonstration of antiproliferative and cytotoxic effects of DNAi oligonucleotides and selection of PNT100

Oligonucleotide sequences targeted along the $5^{\prime}$ region upstream of the BCL-2 ATG start site were synthesized and tested for antiproliferative activity against breast and melanoma cell lines. The oligonucleotides ranged from 20 to 26 bases in length, contained 61-100\% CG content, and mapped within the region translocated during the $\mathrm{t}(14 ; 18)$ rearrangement. The oligonucleotides were methylated at the cytosine bases when used in cell exposure studies. The sequences were identical to the non-template strand and $100 \%$ complementary to the template strand of genomic 
DNA. Of the oligonucleotides tested, a 24-base sequence of 5'-CAXGCAXGXGCATCCCXGCCXGTG-3' showed the broadest antiproliferative effects against a panel of breast (67-76\% inhibition) and melanoma (42-65\%) cell lines (see Supplemental Figure S1A). This oligonucleotide also showed robust and time-dependent cytotoxic effects in WSU-FSCCL (see Supplemental Figure S1B), a fast growing BCL-2 and CMYC-driven non-Hodgkin's follicular lymphoma cell line characterized by the BCL-2 $t(14 ; 18)$ $(\mathrm{q} 32 ; \mathrm{q} 21)$ and CMYC $\mathrm{t}(8 ; 11)(\mathrm{q} 24 ; \mathrm{q} 21)$ rearrangements [31]. Furthermore, BL2 (which represents methylated PNT100) and BL7 were counterscreened against an immortalized normal mouse mammary gland cell line (NMuMG, see Supplemental Figure S1C). BL2 (mePNT100) did not result in cytotoxicity at either 24 or $96 \mathrm{~h}$ post-exposure, whereas BL7 showed significant cytotoxicity at $96 \mathrm{~h}$ postexposure. The lack of cytotoxicity in BL2 suggests specificity for the human sequence. This 24-base sequence was nominated as a lead BCL-2 therapeutic candidate and further tested for sequence specificity.

\section{In vitro sequence specificity testing of PNT100}

To determine whether methylation was necessary for antiproliferative and cytotoxic effects, mePNT100 and unmethylated PNT100 were combined with a transfection agent, NeoPhectin AT, and the cytotoxic effects against PC-3 cells were tested (see Fig. 1a). The results showed equal activity between mePNT100 and PNT100, with approximately a $50 \%$ reduction of cell proliferation post-exposure. Furthermore, the activity of PNT100 was compared to randomer, mismatched, and a reverse control of PNT100 (PNT100R) oligonucleotide controls. With the exception of the scrambled control, all sequences tested had identical 3 'termini to control for any non-specific toxicity that has been reported due to the release of terminal bases [32]. Data show minimal antiproliferative effect of these oligonucleotides when compared to saline control (see Fig. 1a), with PNT100 or mePNT100 having the greatest effect. The activity was not influenced by the presence of 5-azacytidine, an inhibitor of DNA methyltransferase activity (Fig. 1a, right panel), indicating that the effect was not methylation dependent [33]. Further, BCL-2 expression following exposure with PNT100 was compared to the scrambled control (Fig. 1b).

To develop PNT100 as an intravenous drug candidate, liposomes were chosen to protect the unmodified oligonucleotide, enhance its pharmacokinetic profile, and facilitate cellular delivery. Initially, NeoPhectin was evaluated. The lipid components in NeoPhectin are similar to LErafAON, a liposome-encapsulated antiraf antisense oligonucleotide developed by NeoPharm [34]. PNT100 formulated with NeoPhectin demonstrated antitumor activity against WSU-DLCL2 xenografts and reduced BCL-2 expression in excised tumors when assessed 26 days post-treatment (Fig. 1c) when compared to liposome controls (NeoPhectin alone) or the reverse sequence of PNT100 formulated with NeoPhectin (NeoPhectin PNT100R). PNT100 formulated with NeoPhectin (NeoPhectin PNT100), however, did not demonstrate consistent stability when exposed to serum or physicochemical characteristics suitable for development as an oncology therapeutic. Therefore, candidates for a new delivery system were screened.

Evaluation of amphoteric liposomes and optimization

The SMARTICLES ${ }^{\circledR}$ platform represents a series of liposomes having amphoteric properties (i.e., $\mathrm{pH}$-dependent prevalence of either acidic or basic groups) that may be modulated across physiological $\mathrm{pH}$ ranges. This platform showed promising serum stability and proven tissue delivery with broad cellular localization, including nuclear delivery [26]. A number of lipid compositions including $\mathrm{pH}$-sensitive cationic or anionic, fusogenic, and bilayer/ stabilizing lipids were tested. Formulations that met criteria of $>50 \%$ encapsulation, $<15 \%$ serum release, $<200 \mathrm{~nm}$ particle size, and $<0.2$ poly-dispersity underwent further testing in xenograft models. Encapsulated PNT100 and PNT100R were tested for antitumor activity against PC-3 xenografts as single agents and in combination with docetaxel (Fig. 2a). As single agents, all formulations containing PNT100 showed activity (labeled as 1,2, or 3) with formulation 1 and 2 showing greater activity than 3 , but equivalent tumor growth delay. Less activity was observed with formulations containing PNT100R (labeled as 1R, 2R, or $3 \mathrm{R})$. Formulation 1 was chosen because (1) it showed good single-agent activity and an additive effect with encapsulated PNT100 when combined with docetaxel and (2) the liposome formulation showed the least antitumor activity with PNT00R as a single agent or in combination with docetaxel. Therefore, based on the results from this activity screen and the physicochemical characterizations, a composition of POPC, DOPE, CHEMS, and MOCHOL at molar ratios of 6:24:23:47 was chosen for PNT2258.

Due to the robust and consistent single-agent activity observed, the drug product characteristics of PNT2258 were optimized in vivo against WSU-DLCL2 tumor xenografts. A broad dose range was tested (Fig. 2b). However, as seen, at doses of $\sim 10 \mathrm{mg} / \mathrm{kg}$, increasing the dose further did not produce additional antitumor activity, and increasing the dose even further produced frank toxicity in the experimental animals. These data suggested that the dose-response curve for PNT2258 is relatively flat in mice over the effective dose range and is consistent with dose-dependent pharmacokinetics and therapeutic efficacy often seen with liposome-delivered therapeutics once saturation or clearance blockade is achieved [36]. The effects 


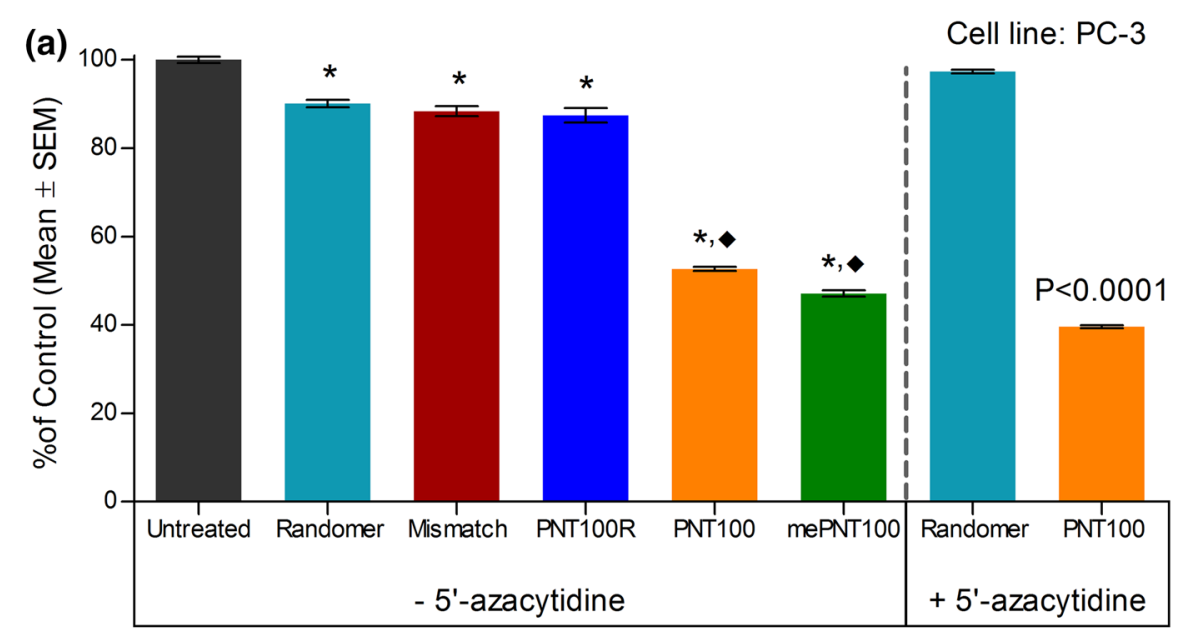

(b)

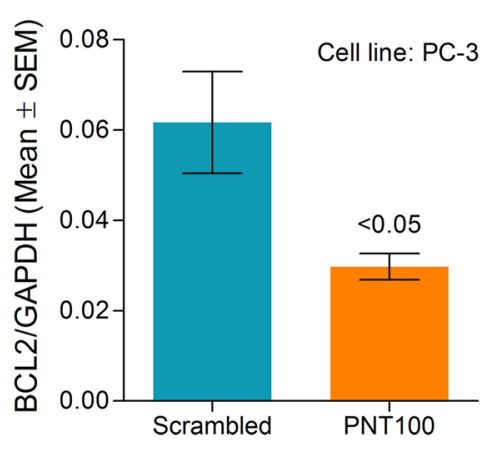

(c)

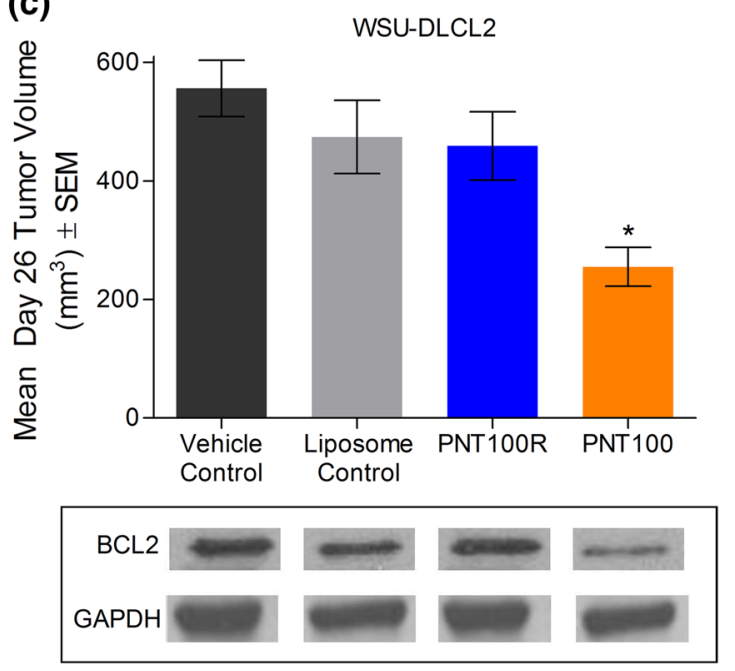

Fig. 1 Effect of PNT100 or controls formulated with NeoPhectin on cell proliferation, BCL-2 expression, and antitumor activity. a Left panel PC-3 prostate cancer cells were exposed to $10 \mu \mathrm{M}$ PNT100 (triplicate per group), methylated PNT100, and controls. After $6 \mathrm{~h}$ of exposure, cells were washed and allowed to equilibrate and analyzed $48 \mathrm{~h}$ post-exposure by Cell Titer-Glo assay. ${ }^{*} P<0.001$ versus control, $P<0.001$ versus scrambled, mismatched, randomer, and reverse control (PNT100R). a Right panel in a separate experiment, PC-3 prostate cancer cells were exposed to $5 \mu \mathrm{M} 5^{\prime}$-azacytidine in combination with $10 \mu \mathrm{M}$ PNT100, randomer or scrambled control. After $72 \mathrm{~h}$ of exposure, cells were analyzed for viability by Cell Titer-Glo assay. $P<0.0001$ versus scrambled or randomer control. b BCL-2 levels in PC-3 prostate cancer cells exposed to PNT100

of PNT100-to-lipid ratio, particle size, size distribution, and freezing on antitumor activity were testing iteratively in WSU-DLCL2-tumored mice and these are summarized in Table 1. Pre-optimization formulations administered IV for five consecutive days at a $10 \mathrm{mg} / \mathrm{kg}$ PNT100 equivalent dose (q5d) resulted in a TGD of $0-13$ days and net $\log _{10}$ cell kills of $0-0.5$ across the doses tested. Net kill is the change in tumor burden $(\operatorname{logs})$ over the treatment period and the scrambled control $(10 \mu \mathrm{M})$. After $6 \mathrm{~h}$ of exposure, BCL-2 and GAPDH RNA expressions were analyzed via qPCR. $* P<0.05$ versus scrambled control. c Mean tumor size in animals following intravenous administration (IV, via tail vein) of $10 \mathrm{mg} / \mathrm{kg}$ PNT100 (NeoPhectin PNT100), reverse control (NeoPhectin PNT100R) or the vehicle controls (saline or NeoPhectin liposomes). WSU-DLCL2 tumor xenografts were implanted subcutaneously into animals and allowed to grow to an average of $100 \mathrm{~mm}^{3}$ size prior to treatment with five daily doses. Animals ( $n=8$ for all groups) were killed 26 days post-dosing, mean tumor weights measured, and BCL-2 protein levels were analyzed using protein immunoblots. $* P<0.05$ versus Saline control, NeoPhectin Liposome control, and NeoPhectin PNT100R

and enables the quantitative comparison of efficacy across experimental protocols by normalizing the efficacy data for treatment regimens of varied duration and differences in tumor growth rates between experiments or models. Positive values indicate a reduction of tumor burden occurred at the end of therapy relative to the pre-treatment burden. Post-optimization formulations (designated as PNT2255 or PNT2256) resulted in a TGD of $23-36$ days, net $\log _{10}$ 


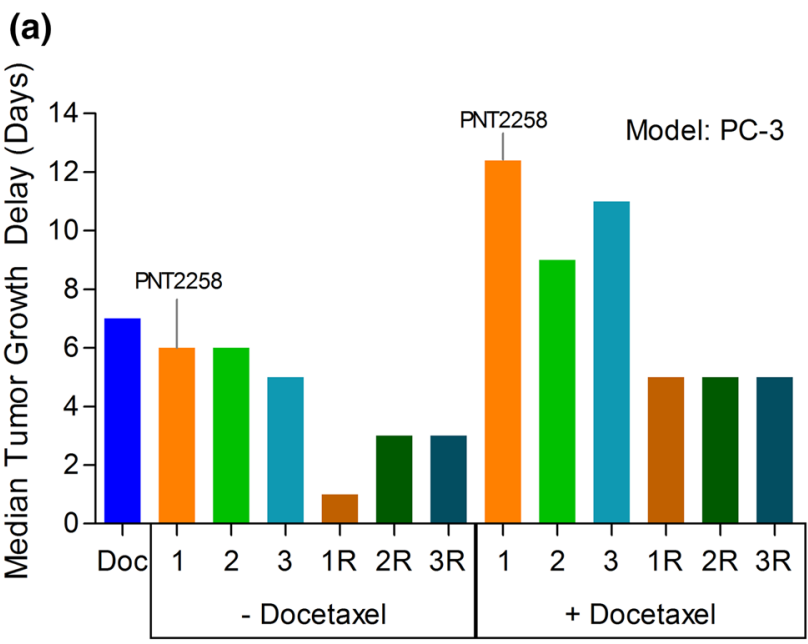

(b)

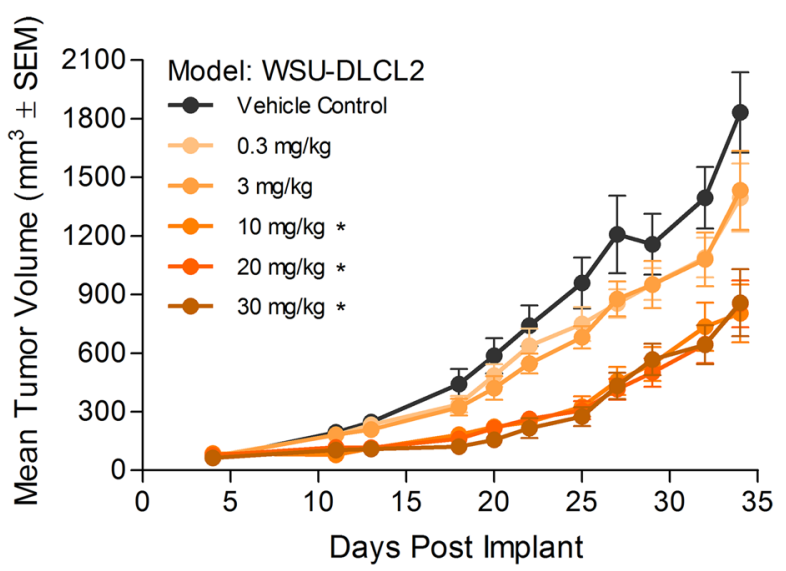

Fig. 2 Antitumor activity against xenograft tumors of several formulations of PNT100 or PNT100R encapsulated in SMARTICLES (amphoteric liposomes) and the dose response of PNT100 in the chosen formulation. a SCID/NCr mice were implanted with PC-3 cells and treated with vehicle (saline) control, PNT100R or PNT100 encapsulated in three different lipid compositions as a single agent or in combination with docetaxel. PNT100, PNT100R, and the vehicle control were administered IV at $10 \mathrm{mg} / \mathrm{kg}$ daily for 5 days. Docetaxel was dosed at 2 and $5 \mathrm{mg} / \mathrm{kg}$ on day 2 and 5, respectively. Bars represent the median tumor growth delay ( $n=5$ for all groups). Various liposome formulations with PNT100 are represented as numbers (i.e., 1, 2, and 3), while the corresponding formulations with PNT100R are designed with "R" (i.e., 1R, 2R, and 3R). Formulation 1 is PNT2258. b Dose response of prototype PNT2258 (PNT100 encapsulated in lipid composition chosen for PNT2258, pre-optimization). SCID mice were implanted with WSU-DLCL2 cells and administered IV with saline (vehicle control) or prototype PNT2258 at doses ranging from 0.3 to $30 \mathrm{mg} / \mathrm{kg}$ (based on OD260 total oligonucleotide content). Mean tumor volumes following treatment ( $n=7$ per group) are shown. $* P<0.05$ versus vehicle control and prototype PNT2258 at 0.3 and $3 \mathrm{mg} / \mathrm{kg}$. Improvements made from pre-optimization to postoptimization resulted in an increase in tumor growth delay from 9 to 21 days and an increase in net cell kill from 0.2 to 1.1 using the same dose $(10 \mathrm{mg} / \mathrm{kg})$ and schedule (QDx5) cell kills of 1-2, and a proportionate increase in complete responses and tumor-free survivors (Table 1). Of note, targeting average particle diameters of $\sim 130 \mathrm{~nm}$ and changing PNT100-to-lipid ratios to 1:25 from 1:50 improved activity. Process refinements (mixing conditions, extrusion to refine particle size, and polydispersity) were applied, and these prototype formulations were tested at doses of $10 \mathrm{mg} / \mathrm{kg}$ to define the physicochemical characteristics of encapsulated PNT100. The efficacy of frozen versus refrigerated formulations of PNT2258 alone or in combination with rituximab showed that freezing the formulation demonstrated at least equivalent activity and equivalent physicochemical characteristics upon thawing when compared to the refrigerated formulation, indicating that freezing did not affect activity (Table 1). Therefore, freezing was implemented as the final step during manufacturing to enhance shelf life. The resulting nanoparticles with a diameter of approximately $130 \mathrm{~nm}$ encapsulating PNT100 at an oligonucleotide-to-lipid ratio of 1:25 (w/v) was designated as PNT2258.

Pharmacokinetics, tissue distribution, and immune evaluation of PNT2258

PNT100 and PNT2258 were shown to be stable in whole blood for at least $24 \mathrm{~h}$ at $37^{\circ} \mathrm{C}$. Detergent addition and heating samples at $90{ }^{\circ} \mathrm{C}$ were required prior to being able to detect PNT100 in PNT2258 by the hybridization-ligation method. Further, no degradation of spiked PNT100 or PNT2258 was observed with long-term storage at $-80{ }^{\circ} \mathrm{C}$ (>200 days). In effect, no unencapsulated PNT100 is detected in plasma obtained post-intravenous administration. Pretreatment of plasma or tissue samples post-IV administration to release PNT100 from PNT2258 suggests that the nanoparticle remains intact. Similar findings were noted with PNT100, PNT2258, or PNT2258cy (encapsulated cynomolgus monkey-specific sequence of PNT100) visualized by SYBR Green post-24 h exposure in whole blood (Nanotechnology Characterization Laboratory (NCL), unpublished results). Dose-proportional plasma exposure in $\mathrm{BALB} / \mathrm{c}$ mice treated with 3,10 , or $20 \mathrm{mg} / \mathrm{kg}$ PNT2258 was seen with area under the curve values of $22,377,219,986$ or $1,588,000 \mathrm{ng} \mathrm{h} / \mathrm{mL}$ and $C_{\max }$ values of $16,585,37,250$ or $151,088 \mathrm{ng} / \mathrm{mL}$, respectively. Half-lives ranged from 2.5 to 9 h. Plasma concentrations for each of the three doses are shown in Fig. 3a. The pharmacokinetic profiles of PNT2258 $(20 \mathrm{mg} / \mathrm{kg})$ as a single agent $\left(C_{\max } 148,331 \mathrm{ng} / \mathrm{mL}\right)$ or in combination with rituximab $\left(C_{\max } 120,256 \mathrm{ng} / \mathrm{mL}\right)$ in SCID mice with Daudi xenografts were similar to the BALB/c profile, demonstrating a consistent pharmacokinetic profile between naïve and xenografted animals. 


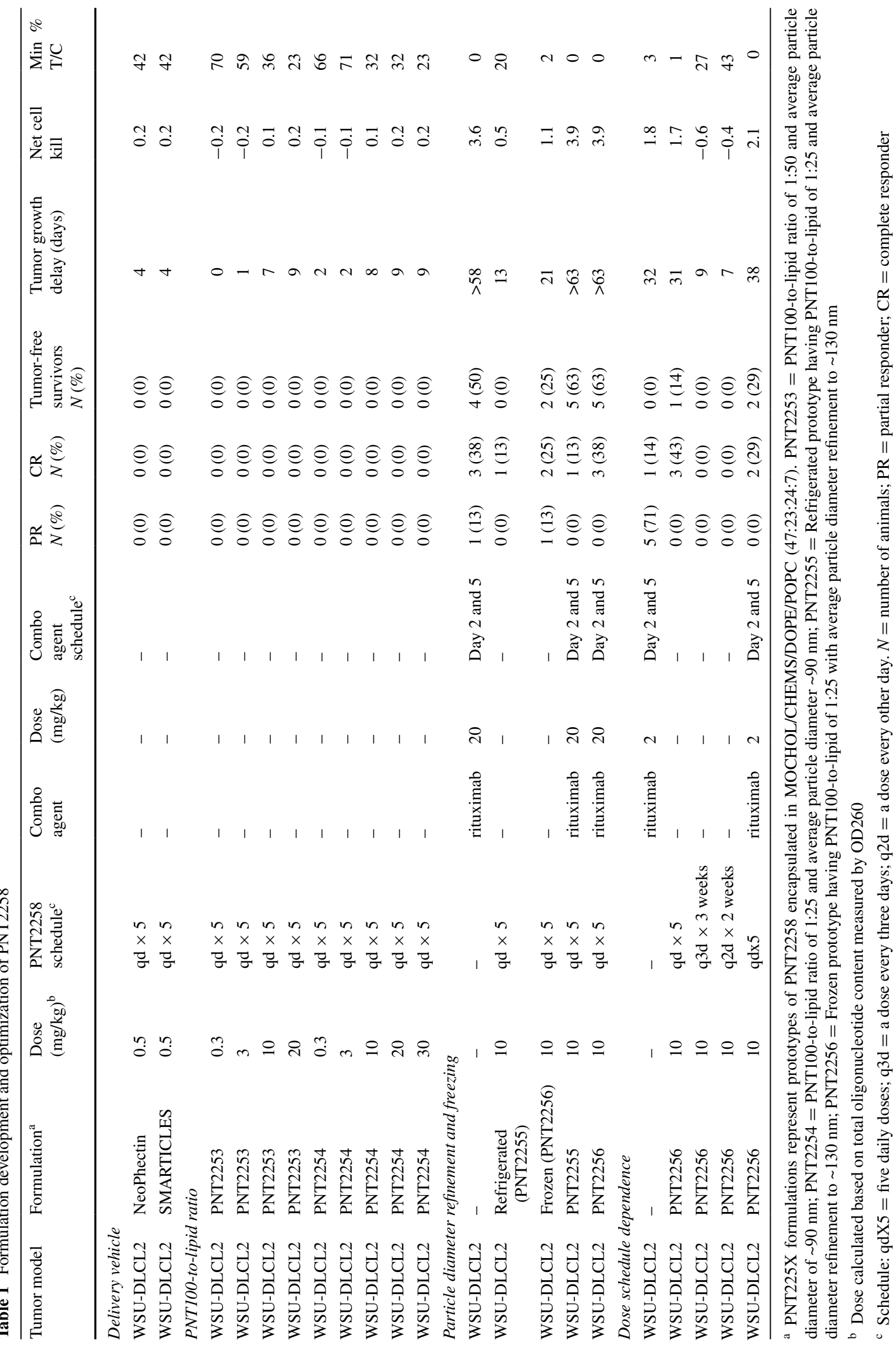


Fig. 3 Pharmacokinetics, tissue distribution, and time course of cellular uptake of PNT2258. a Pharmacokinetics of PNT2258 in BALB/c or SCID Daudi-Burkitt's-tumored mice measured in plasma by the hybridization-ligation assay. PNT2258 was administered IV as a single dose at 3,10 , or $20 \mathrm{mg} / \mathrm{kg}$ ( $n=3 /$ group $)$ in BALB/c mice (data shown in orange). PNT2258 was administered as a single dose at $20 \mathrm{mg} / \mathrm{kg}$ as a single agent or in combination with a single dose of rituximab $(20 \mathrm{mg} / \mathrm{kg}) . N=3$ or 4 per group, data shown in blue. Both agents were administered IV within $5 \mathrm{~min}$ of each other. Blood was collected at 5, 15, $30 \mathrm{~min}, 1,2,4,8$, and $24 \mathrm{~h}$ and plasma was stored at $-80{ }^{\circ} \mathrm{C}$ until analysis. b Tissue distribution of PNT2258 in WSU-DLCL2-tumored mice. Nude mice were implanted with WSUDLCL2 cells and administered IV with $20 \mathrm{mg} / \mathrm{kg}$ PNT2258. Tissue samples were collected at $8 \mathrm{~h}$ after the initial treatment for analysis by gel capillary electrophoresis visualized by hybridization with a PNT100-specific fluorescent probe. Blood was collected $8 \mathrm{~h}$ postdose and plasma was analyzed by the hybridization-ligation assay. $\mathbf{c}$ Time course of HeLa cell uptake of Cy5.5-labeled PNT100 or encapsulated Cy5.5-labeled PNT100 (representative of PNT2258) monitored by light phase and confocal microscopy

The tissue distribution of PNT2258 levels measured after homogenization of tissues and quantified using capillary gel electrophoresis to detect the hybridization of PNT100 with its specific fluorescent probe is shown in Fig. 3b. A consistent with pharmacokinetic clearance, at $8 \mathrm{~h}$ post-dose the liver $(\sim 10 \%)$, spleen $(\sim 12 \%)$, and blood represented approximately $40-50 \%$ of the injected dose with the remainder across a broad tissue distribution including uptake in tumors of WSU-DLCL2 tumor-bearing mice. The uptake of PNT2258 into HeLa cells is shown in Fig. 3c. HeLa cells were used to demonstrate PNT2258 uptake because these cells are relatively resistant to PNT2258induced cytotoxicity, thereby allowing a time course of uptake to be conducted. Based on the qualitative formulation screen of antitumor activity, physicochemical results, ease of preparation, and in vivo tumor cell localization, the lipid composition to encapsulate PNT100 was selected and further optimized.

The sequence specificity of PNT100's antitumor activity in amphoteric liposomes was reconfirmed by demonstrating antitumor activity of PNT2258, but not control oligonucleotides (Fig. 4a). Unmodified oligonucleotides, being natural structures, are quickly degraded and eliminated if not protected (e.g., within a liposomal formulation like PNT2258) and are generally not toxic even at high doses. However, liposomal encapsulation alters the innocuous nature of an unmodified oligonucleotide and published reports suggest encapsulation enhances immunostimulatory properties especially in rodents. While PNT100 contains $\mathrm{CpG}$ sequences, it does not contain known motifs that are immunostimulatory. Therefore, to eliminate a concern that immune stimulation was driving PNT100's BCL2-targeted antitumor activity, a parallel set of xenografted animals were treated with either PNT2258 or encapsulated (a)
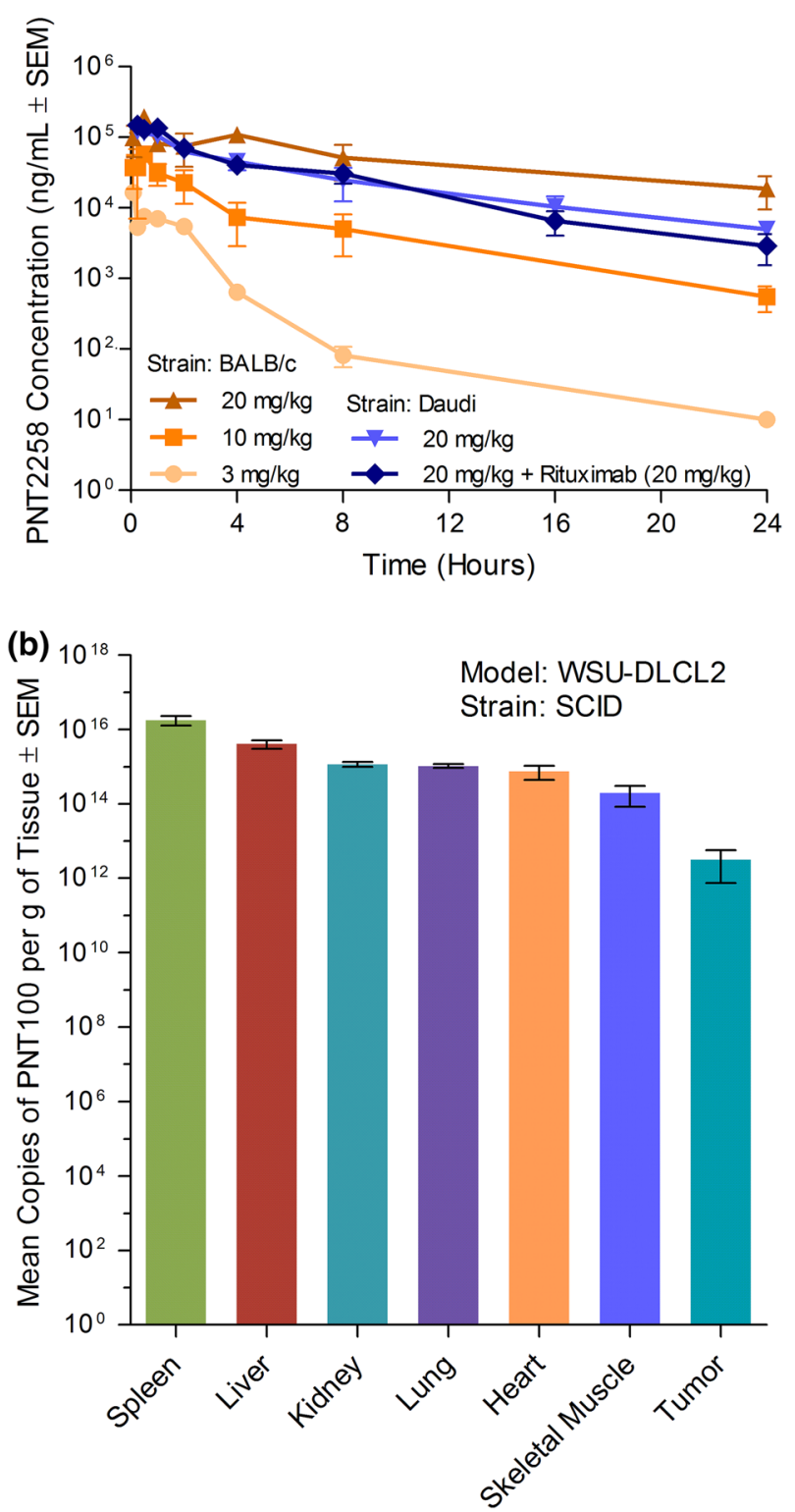

(c) Cy5.5-labeled PNT100

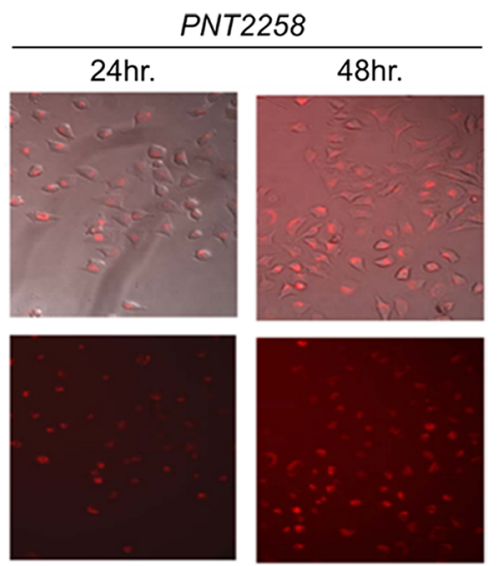


(a)

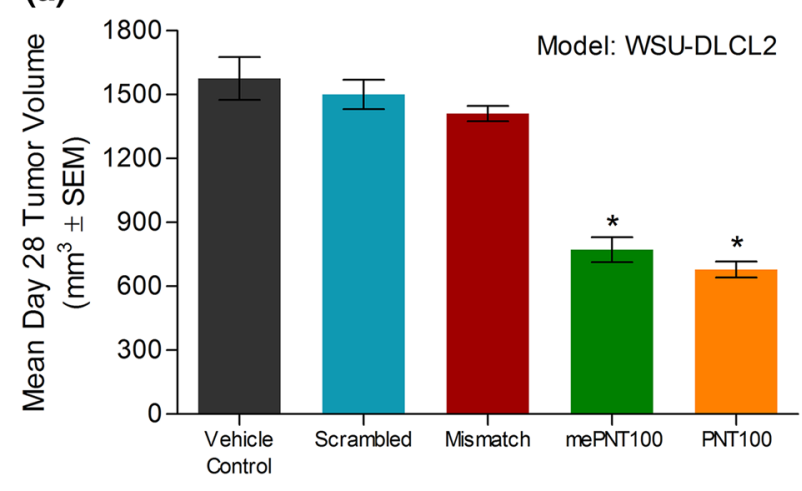

(c)

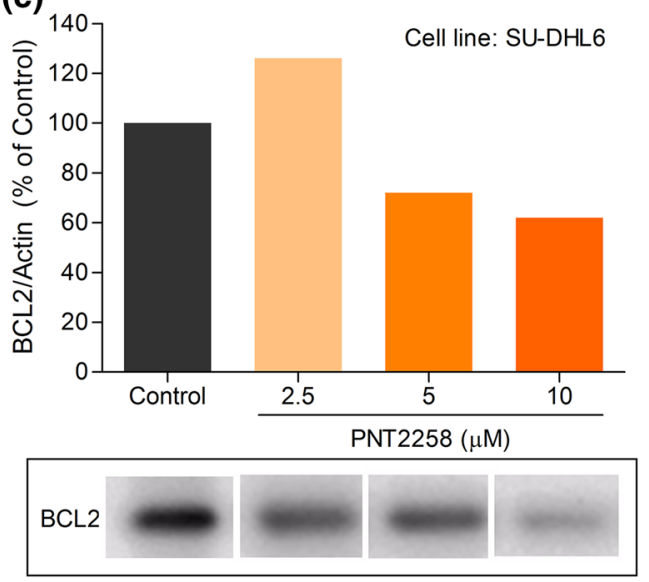

(b)

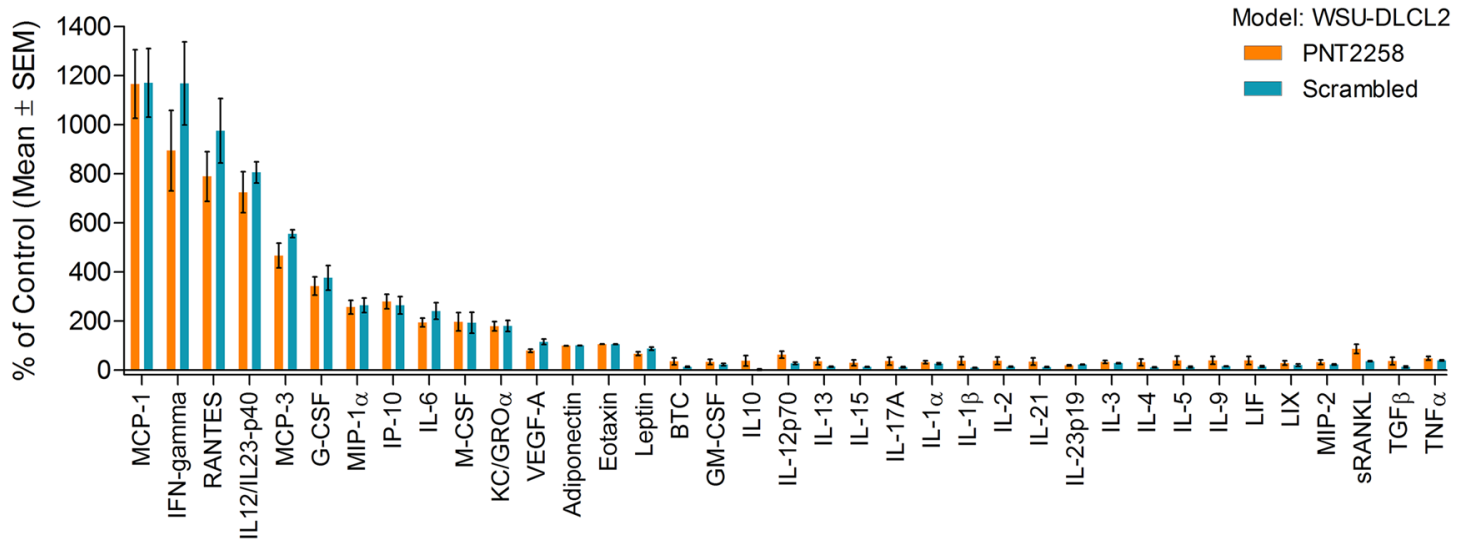

Fig. 4 Antitumor activity and plasma immune markers following the administration of PNT100 or control oligonucleotides encapsulated in the lipid composition chosen for PNT2258. a Mean tumor volume in SCID mice-bearing WSU-DLCL2 xenografts at 28 days posttumor implant following IV treatment $(10 \mathrm{mg} / \mathrm{kg}$ for 5 consecutive days) with PNT100, methylated PNT100, scrambled, mismatched, or vehicle control ( $n=8$ for all groups). ${ }^{*} P<0.05$ versus vehicle, scrambled, and mismatched controls. b Plasma immune markers in WSU-DLCL2-tumored animals following a single dose of PNT2258 $(n=5)$ or encapsulated scrambled $(n=5)$ control represented as a percent of control (saline-treated $n=5$ ). Similar profiles and magni-

scrambled control, and plasma was obtained $24 \mathrm{~h}$ postdose and tested for immune marker modulation (Fig. 4b). PNT2258 and the scrambled control produced similar immune responses in tumor-bearing immune-compromised mice. Markers indicative of innate immune stimulation (IFN $\gamma$, IL-6, IL-12p40, IP-10, RANTES) and nanoparticle recognition (MCP-1, MCP-3, G-CSF) were increased following dosing. These findings support a BCL-2-targeted antitumor effect as a result of treatment with PNT2258 and rule out a non-specific immune response driving xenograft antitumor activity. Additional studies exposing PNT100, PNT2258, encapsulated scrambled control, PNT228cy, or empty liposomes to human PBMCs, and probing with tude of response were seen with PNT2258 and the scrambled control. The only significant difference in marker expression between the two treatment groups was in IFN $\gamma(* P<0.05)$. MCP-1, IFN $\gamma$, RANTES, IL12/IL23-p40, MCP-3, and G-CSF were all significantly different in both treatment groups compared with the other 31 markers $(\diamond P<0.05)$. c SU-DHL6 lymphoma cells were exposed to PNT2258 at $2.5,5$, and $10 \mu \mathrm{M}$. After $72 \mathrm{~h}$ of exposure, the contents of triplicate wells were pooled for the BCL-2 protein by immunoblots. The bar graph above the blots represents the densitometric quantification of the BCL-2 protein normalized against actin protein levels

a broad immunoplex panel demonstrate modest immune stimulation and are attributed to the recognition of the amphoteric liposome carrier (data not shown and unpublished results, NCL Collaboration). The modulation of BCL-2 following incubation with PNT2258 was confirmed in a SU-DHL-6 lymphoma cell line (Fig. 4c).

Dose schedule effects of pre-optimized PNT2258 on antitumor activity

Three treatment schedules, daily for 5 days (QDx5), every other day with seven doses (Q2Dx7), and every third day with eight doses (Q3Dx8), at $10 \mathrm{mg} / \mathrm{kg}$ were evaluated 
against WSU-DLCL2 xenograft tumors (see Fig. 5). Tumor growth delay (Fig. 5a) and net $\log _{10}$ tumor cell kill (net kill; Fig. 5b) as a secondary efficacy endpoint were used to compare the activity between treatments. The QDx5 treatment schedule produced a tumor growth delay in excess of 31 days with a corresponding net kill of $1.7 \operatorname{logs}$, while the tumor growth delay values for the other two treatment schedules were less than 10 days and had negative net kill values, indicating tumor progression. These data suggested the QDx5 treatment schedule was superior and prompted the use of the daily, 5 days treatment schedule in future studies in xenograft studies. The maximum-tolerated dose (MTD) of PNT2258 prototypes was generally $20-30 \mathrm{mg} / \mathrm{kg}$ and was xenograft model independent. The MTD is defined at the dose that produces less than $20 \%$ weight loss and is less than or equal to the LD10 in the experimental animals. Weight loss induced by PNT2258 was dose responsive, but never exceeded $20 \%$. Further, in other testing paradigms, additional treatment cycles were added so that the experimental animals received PNT2258 5 days per week for three consecutive weeks. No dose-limiting toxicities, assessed by body weight changes, were noted between groups.

\section{PNT2258 activity across tumor xenograft models}

The activity of PNT2258 was tested as a single agent or in combination with docetaxel or rituximab across four xenograft models, WSU-DLCL2 lymphoma, Daudi-Burkitt's lymphoma, PC-3 prostate, and A375 melanoma and are summarized in Fig. 6a and Supplemental Table 1. WSUDLCL2 xenografts are representative of a lymphoma cell line harboring the $t(14 ; 18)$ rearrangement with constitutive NF- $\kappa \mathrm{B}$ activation driving not only proliferation, but also increased BCL-2 transcription. Daudi-Burkitt's xenografts harbor a $(\mathrm{t} 8 ; 14)$ rearrangement and is primarily a CMYCdriven lymphoma subtype. PC-3 xenografts represent a radioresistant model, attributed to increased BCL-2 transcription [35]. A375 is a human-derived melanoma cell line harboring a BRAF mutation due to the substitution of valine for glutamic acid at codon 600 , termed V600E resulting in constitutive activation, aggressive proliferation, and high BCL-2 expression. The tumor growth curves for control (saline), PNT2258, docetaxel, or rituximab as single agents or combination treatments are presented in the left panels, with overall survival shown in the corresponding right panels. Generally, weight loss induced by PNT2258 was dose dependent, but average treated body weights did not decrease below $20 \%$ of baseline at any dose as a single agent or in combination with cytotoxic agents.

To compare the activity across models, the data are also represented as gross cell kill (Fig. 6b). Models are represented from left to right based on the single-agent activity of PNT2258 (leftmost bar of each set), and interestingly, an
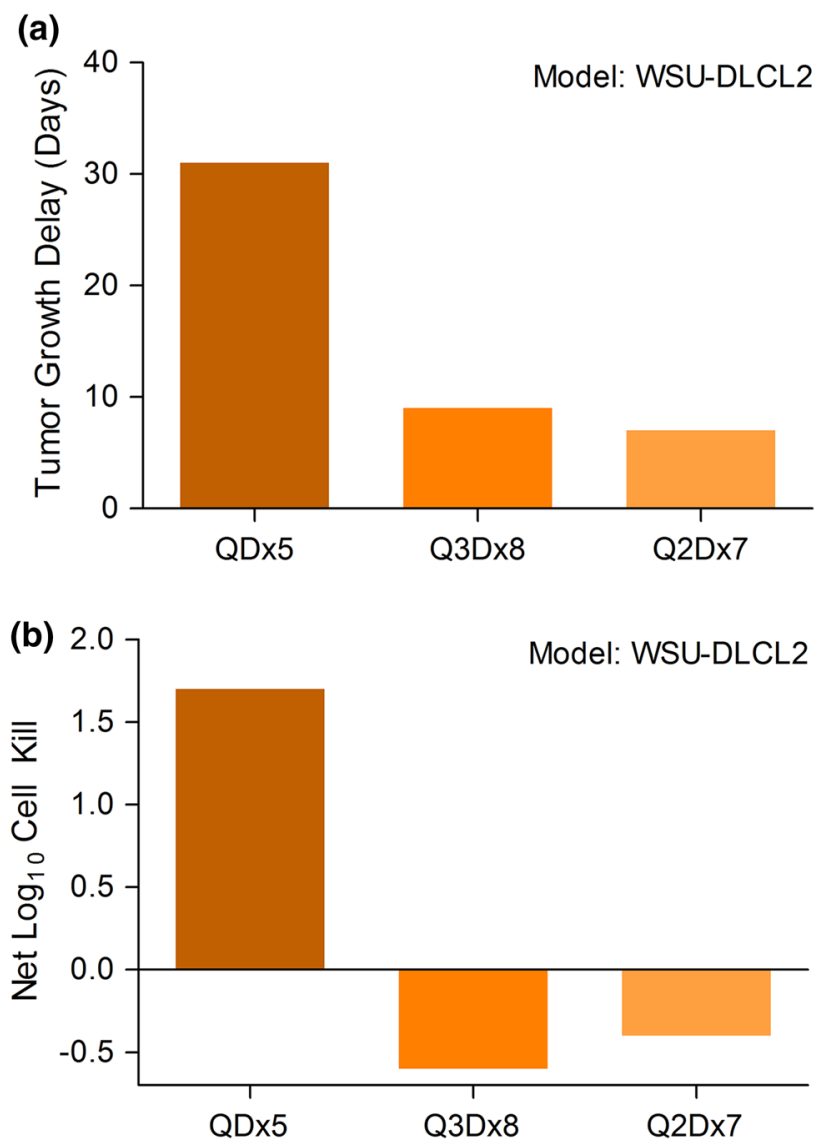

Fig. 5 The effect of dose schedule on antitumor activity. a Tumor growth delay in C.B-17 SCID mice-bearing WSU-DLCL2 xenografts following administration of $10 \mathrm{mg} / \mathrm{kg}$ PNT2258 at the following dose schedules: five IV daily doses (QDx5), 8 IV doses given every third day (Q3Dx8), and 7 IV doses given every other day (Q2Dx7) $(n=7$ for all groups). b Net $\log _{10}$ cell kill calculated for each dose schedule. A positive net $\log _{10}$ cell kill indicates a decrease, while a negative net $\log _{10}$ cell kill indicates an increase, in the tumor cell population at the end of treatment compared with the beginning of treatment

alignment with literature reported BCL-2 protein expression $[1,37,38]$. In some models, there was significant positive interaction between PNT2258 and standard agents (Daudi-Burkitt's and A375). In the PC-3 and DLCL2 models, the interaction was less pronounced. The combination agents were administered at maximum-tolerated doses reported in the literature for each model and based on the testing facilities' historically experiences. This dosing paradigm, instead of using suboptimal combination doses, may account for the lack of synergistic or additive effect in the DLCL2 model because the combination agent was so effective. This is supported in other studies (not shown), where synergistic activity of PNT2258 with docetaxel and rituximab was observed when these agents were used at suboptimal doses. The robust antitumor activity provided the rationale to move PNT2258 further into toxicology evaluation and subsequent clinical development. 
Fig. 6 Antitumor effect and percent survival of animals treated with PNT2258 or combination agent as single agents or in combination across four xenograft models. a PNT2258 or combination agent was tested against PC-3 (prostate, $n=10$ / group), Daudi-Burkitt's (lymphoma, $n=10$ /group), A375 (melanoma, $n=10 /$ group), and WSU-DLCL2 (lymphoma, $n=7 /$ group) alone or in combination. Symbols on the $x$-axis represent days of dosing for each treatment; the same schedules were used in combination. The numbers in parentheses after each compound represent the dose $(\mathrm{mg} / \mathrm{kg})$ administered. All treatments were administered IV. In the PC-3 study, docetaxel was administered at $10 \mathrm{mg} / \mathrm{kg}$ for the initial dose and then at $5 \mathrm{mg} / \mathrm{kg}$ for the subsequent dose. b Gross cell kill $\left(\log _{10}\right)$ across all four xenograft models. Numbers above the bars represent the tumor-free survivors per total animals in the treatment group. The lack of values above a bar indicates that there were no tumor-free survivors for that treatment group
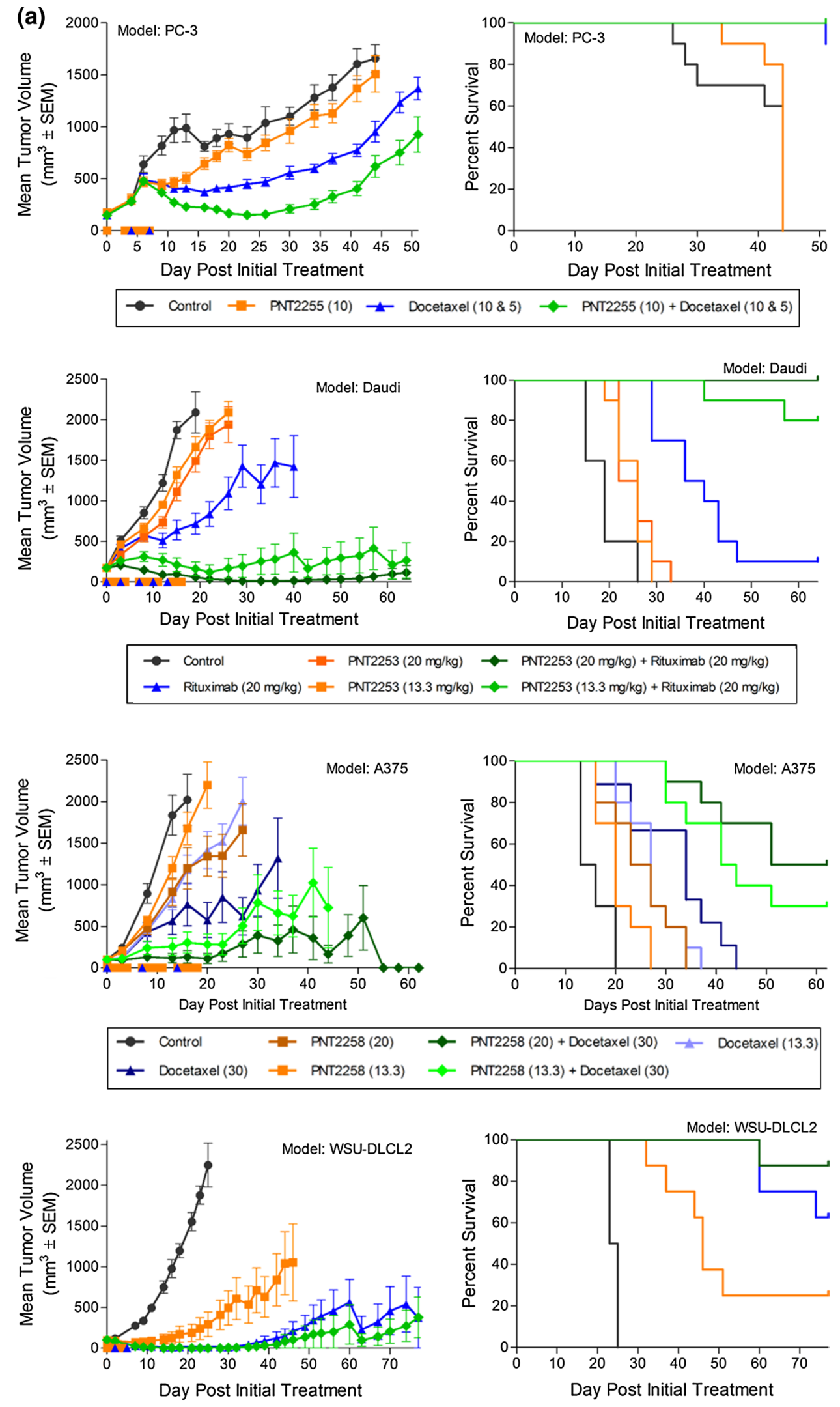

$\multimap$ Control - PNT2258 (10) $\multimap$ Rituximab (20) $\multimap$ PNT2258 (10) + Rituximab (20) 
Fig. 6 continued

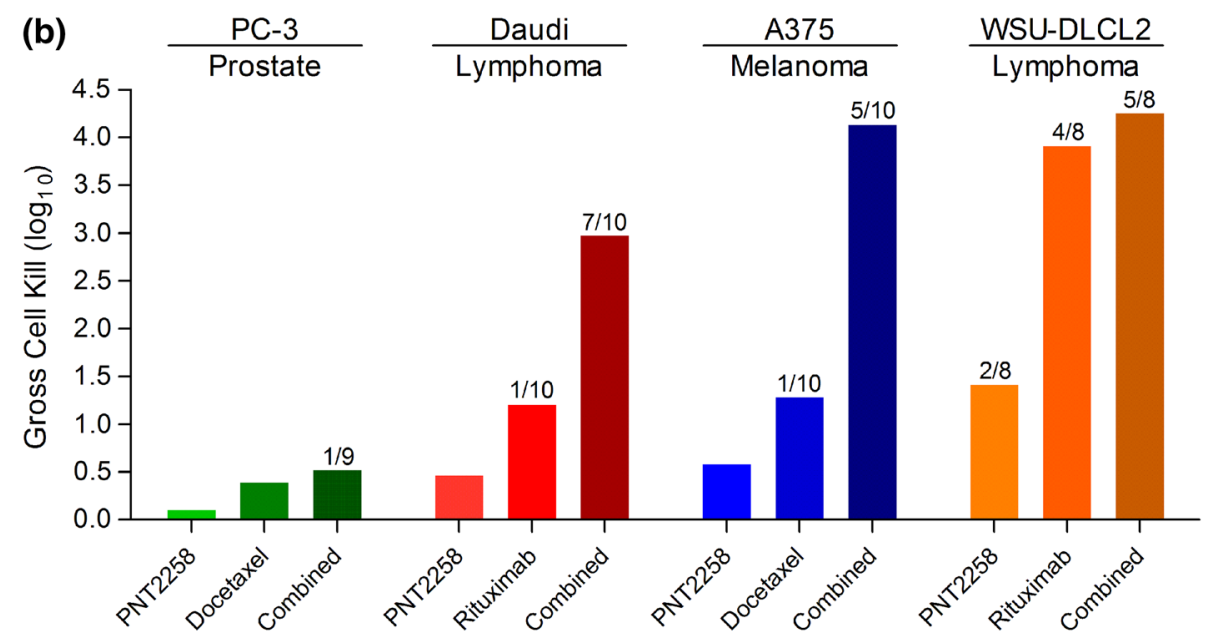

\section{Discussion}

Oligonucleotide candidates modulating gene expression may be targeted at the level of either RNA or genomic DNA. Approaches to modulate genomic DNA include triplex, quadruplex oligonucleotides, methylated forms of DNA or RNA, or mismatched or single-base modifications of the DNA or RNA oligonucleotides. These methodologies hybridize to transcription start sites to interfere with transcription, cause DNA cleavage, homologous recombination or act to stimulate inherent DNA repair mechanisms to correct the mismatches triggered by the hybrid doublestranded DNA/DNA or chimeric RNA/DNA interactions $[38,39]$. To our knowledge, none of these DNA-targeted approaches have progressed into the clinic. In contrast, single- or double-stranded RNA-targeted oligonucleotide approaches have progressed to the point of providing clinical success reviewed in [40] and [41]. These include antisense or siRNA that cause mRNA cleavage and disruption of the RNA translational machinery, RNA modulation agents that correct gene defects by exon skipping, or microRNA miRs and antimiRs agents that regulate the expression of multiple pathways by replacing absent sequences or antagonizing sequences, respectively. A common feature among these approaches is the use of chemical modifications (e.g., phosphothioate, 2'-modified nucleic acids including MOE modifications and cET, conformationally restricted nucleic acids bases including LNA and inverted bases) to enhance activity, pharmacokinetics, and pharmacodynamics [reviewed in [42] ]. In addition, in some cases, the active RNA sequences are not $100 \%$ complementary to their target mRNA.

The 24-base BCL-2-targeted oligonucleotide, PNT100 represents a new class of DNA therapeutics being developed that is distinct from other nucleic acid approaches. PNT100 is an unmodified phosphodiester DNA sequence that is $100 \%$ complementary to its homologous sequence of genomic DNA. Our data demonstrate equivalent antitumor activity of mePNT100 and unmethylated PNT100, but no antitumor effects with control scrambled, randomer, or reverse complement sequences. Moreover, in cellular studies, PNT100's antiproliferative activity was not affected by a methyltransferase inhibitor, suggesting that methylation is not required for activity. Virtually identical immune response to PNT2258 and its scrambled control in xenografted animals suggests that PNT100's sequence specificity and not immunogenicity drives BCL-2 modulation and antitumor activity. It is recognized that there are limitations to truly defining control sequences for PNT100. As such, there is the possibility that interactions between the liposomes and specific oligonucleotide sequences may be responsible for the differential effects seen. However, if these effects exist, they should be dose dependent and should have been observed at doses of $10 \mathrm{mg} / \mathrm{kg}$ encapsulated oligonucleotide, a dose level that shows antitumor activity for PNT2258. Therefore, by demonstrating, the specificity of PNT100's pharmacodynamic activity using two independent liposomal systems compared to empty liposomes, and no effect with encapsulated control sequences suggests this is unlikely.

We propose that using unmodified sequences complementary only to a target gene region may offer advantages. The sequence of PNT100 does not possess toll-like receptor (TLR) immunostimulatory $\mathrm{CpG}$ motifs, a property that precludes the need to use chemical modifications to mask immune recognition. Further, the observation that PNT100 cannot be measured unless the liposomes are disrupted suggests fully encapsulated PNT100 may also contribute to immune avoidance. Indeed, no significant changes in immune-stimulatory cytokines or clinical signs of anaphylaxis observed following dosing of PNT2258 in patients with advanced solid tumors lends support to this approach [27]. Clinically, dose-dependent BCL-2-targeted effects were observed including reductions in lymphocyte counts 
[27]. PNT2258 was well tolerated in the clinic with doses up to $150 \mathrm{mg} / \mathrm{m}^{2}$ (equivalent to $\sim 4 \mathrm{mg} / \mathrm{kg}$ ).

The lipid composition used for PNT2258 with its amphoteric $\mathrm{pH}$-tunable nature has several distinct features. First, the overall particle charge is anionic at blood $\mathrm{pH}$ which prevents aggregation with blood components and eliminates the need for PEGylation. Second, the composition is sterol rich with CHEMS and MOCHOL, providing the cholesterol backbone to anchor the $\mathrm{pH}$ responsive headgroup compositions. Third, ether linkages often used to anchor polyethylene glycol (PEG) or $\mathrm{pH}$ responsive headgroups are not used. Finally, the amphoteric nature enables a transition of charge from cationic to net neutral to anionic or vice versa depending on the microenvironment $[24,26]$. For example, during transient acidic ethanolic conditions used during formulation, there is an overall positive charge to the mixture enabling the efficient encapsulation of the negatively charged PNT100. A shift to $\mathrm{pH} 7.5$ renders an overall anionic charge to the particle, repelling unencapsulated oligonucleotide, which is removed during ultrafiltration. The PNT2258 drug product typically has a zeta potential of $-40 \mathrm{mV}$. The anionic surface characteristics and unique lipid composition enables stable encapsulation of the oligonucleotide, without surface PNT100, thereby obviating the need for PEG spacers to prevent aggregation or immune recognition. Additionally, the anionic nature likely alters opsonin adhesion or activation (e.g., complement factors) compared with cationic carriers [43]. It may also attract exchangeable apolipoproteins such as apoE to facilitate cellular uptake through lipoprotein and/or other receptor-mediated uptake pathways [44 and references therein]. The novel lipid MOCHOL has been shown to have a pKa of approximately 6.5 [26], which is within the range identified for facilitating endosomal escape [44]. We believe the unique features of the lipids and the ratios of the liposomal system permits PNT2258, under the appropriate $\mathrm{pHs}$ and ionic environments to facilitate endosomal escape, a key feature enabling PNT100 access to nuclei.

PNT2258 exhibits good systemic exposure following intravenous administration and demonstrates antitumor activity against xenografted tumors. Our working hypothesis centered on the assumption that BCL-2 expression is generally low in non-cancerous cells and entry of PNT100 into non-cancerous tissue would not interfere with normal homeostasis. Similarly, in tumor types driven by BCL-2 transcription, PNT2258 should demonstrate good single-agent activity (compare WSU-DLCL2 with Daudi-Burkitt's), but should potentiate the combination drug in tumor types with high BCL-2 expression if BCL-2 resistance is implicated in disease resistance (e.g., Daudi, PC-3, and A375). The key challenge was to achieve sufficient systemic exposure while avoiding dose-limiting lipid toxicity. Therefore, an overriding goal was to ensure that sufficient lipid doses $(>100 \mathrm{mg} / \mathrm{kg}$ lipid, equivalent to $4 \mathrm{mg} / \mathrm{kg}$ PNT2258) could be safely administered to animals to overcome the reticuloendothelial system (RES) clearance mechanisms and enable sufficient exposure to be efficacious without causing observable toxicities. Lipid particle numbers are proportional to the nanoparticle diameters [45] and both these parameters greatly influence circulation lifetimes [46], hepatic uptake [47], and importantly, tolerability and access to extrahepatic tissues in the absence of targeting ligands [48, 49]. Moreover, the pharmacokinetics and tissue access of liposomes are also influenced by surface charge and recognition which are a function of particle size and composition [46]. Liver fenestrae and sinusoids across species represent physical barriers of $\sim 100 \mathrm{~nm}$ such that nanoparticles with an average diameter size range of $\sim 130 \mathrm{~nm}$ will be primarily removed by resident macrophages and will not readily access hepatocytes, which represent the population of liver cells to which lipid toxicity is attributed [47]. As a result, the liver is generally resilient and can tolerate lipid doses of $100 \mathrm{mg} / \mathrm{kg}$ or greater, depending on the rate of delivery, as evidenced by the safety and tolerability of parenteral nutrition containing daily lipid doses of up to $60 \mathrm{~g}$ (administered at $2.5 \mathrm{~g} / \mathrm{h}$ ). These factors were taken into account during the development of PNT2258 to ensure that a broad therapeutic window could be identified. This is evidenced by the relatively flat dose response of PNT2258 above $10 \mathrm{mg} / \mathrm{kg}$ (EC50 estimated to be between 3 and $10 \mathrm{mg} / \mathrm{kg}$ across the models) and tolerability with daily doses of $30 \mathrm{mg} / \mathrm{kg}$ (or $750 \mathrm{mg} /$ $\mathrm{kg}$ lipid). We speculate that the unique mixture of lipids (that lack ether linkages or PEG) and particle size of the amphoteric liposomes contributes to the therapeutic activity of PNT2258 in several ways. These include imparting stability $[24,26]$, surface characteristics which prolong circulation times in blood, and permit metabolic breakdown to enable repeated dosing. Toxicology findings in preclinical studies with PNT2258 showed dose-dependent toxicities that were reversible, and attributable to high doses of lipid $(>300 \mathrm{mg} / \mathrm{kg}$ ) rather than PNT100 [27].

PNT2258 shows broad activity against a variety of tumor types with robust single-agent activity in DLBCL where BCL-2 transcription drives the genesis and survival of the tumors. Antitumor activity and long-term survival in combination with docetaxel or rituximab in chemo-resistant tumors were also demonstrated. BCL-2 overexpression is linked to lower overall survival and adversely influences progression-free survival in subtypes of chemotherapy naïve NHL patients [50]. After front-line R-CHOP therapy, 30-50\% of these patients fail to respond, with BCL-2 expression remaining high in patients with germinal center DLBCL, suggesting the need for BCL-2-targeted interventions. High-risk patients with revised International Prognostic Index (R-IPI) scores of 3-5 or those with double-hit 
(BCL-2/MYC positive) phenotypes demonstrate even worse prognosis with short survival timelines [51]. Moreover, there is a high correlation between BCL-2 expression and the presence of the $t(14 ; 18)$ translocation. Our preclinical data show that PNT2258 demonstrates good single-agent activity and show additive effect with rituximab in DLBCL where the $t(14 ; 18)$ rearrangement exists (WSU-DLCL2) and synergistic activity against Daudi-Burkitt's, suggesting that targeting BCL-2 can potentiate other therapies. Early clinical data indicate antitumor effect in patients whose tumors may be BCL-2 dependent [27]. Similarly, combination with docetaxel results in an additive effect in prostate and melanoma models. These results support the rationale for combining PNT2258 with approved agents such as docetaxel and rituximab to potentiate their cytotoxic activity in tumor types where BCL-2 plays a role in resistance.

Acknowledgments The authors wish to acknowledge Reza Sheiknejad and David Olson for screening BCL-2 oligonucleotides and Christopher Louden for statistical input. We also appreciate the critical review of data by Bruce Zetter, Anthony Tolcher, and Shari Gaylor. We also thank our collaborators at the Nanotechnology Characterization Laboratory (NCL) at the NCI for probing physicochemical characteristics and nanoparticle properties of PNT100, PNT2258, and controls.

Open Access This article is distributed under the terms of the Creative Commons Attribution License which permits any use, distribution, and reproduction in any medium, provided the original author(s) and the source are credited.

\section{References}

1. Reed JC (1994) Bcl-2 and the regulation of programmed cell death. J Cell Biol 124:1-6

2. Davids MS, Letai A (2012) Targeting the B-cell lymphoma/leukemia 2 family in cancer. J Clin Oncol 30:3127-3135

3. Seto M, Jaeger U, Hockett RD, Graninger W, Bennett S et al (1988) Alternative promoters and exons, somatic mutation and deregulation of the Bcl-2-Ig fusion gene in lymphoma. EMBO J 7:123-131

4. Heckman CA, Mehew JW, Boxer LM (2002) NF-kappaB activates $\mathrm{Bcl}-2$ expression in $\mathrm{t}(14 ; 18)$ lymphoma cells. Oncogene 21:3898-3908

5. Tsujimoto Y, Bashir MM, Givol I, Cossman J, Jaffe E, Croce CM (1987) DNA rearrangements in human follicular lymphoma can involve the $5^{\prime}$ or the $3^{\prime}$ region of the bcl-2 gene. Proc Natl Acad Sci USA 84:1329-1331

6. Yonetani N, Ueda C, Akasaka T, Nishikori M, Uchiyama T, Ohno $\mathrm{H}$ (2001) Heterogeneous breakpoints on the immunoglobulin genes are involved in fusion with the $5^{\prime}$ region of BCL-2 in B-cell tumors. J Cancer Res 92:933-940

7. Pickering BF, Yu D, Van Dyke MW (2011) Nucleolin protein interacts with microprocessor complex to affect biogenesis of microRNAs 15a and 16. J Biol Chem 286:44095-44103

8. Iorio MV, Croce CM (2012) MicroRNA involvement in human cancer. EMBO Mol Med 4:143-159

9. Wilson TR, Longley DB, Johnston PG (2006) Chemoresistance in solid tumours. Ann Oncol 17:315-324
10. Thomas S, Quinn BA, Das SK, Dash R, Emdad L et al (2013) Targeting the Bcl-2 family for cancer therapy. Exp Opin Cancer Targets 17:61-75

11. Blackledge NP, Klose RJ (2011) CpG island chromatin: a platform for gene regulation. Epigenetics 6:147-152

12. Deaton AM, Bird A (2011) CpG islands and regulation of transcription. Genes Dev 25:1010-1022

13. Thurman RE, Rynes E, Humbert R, Vierstra H, Maurano MT (2012) The accessible chromatin landscape of the human genome. Nature 489:75-82

14. Maston GA et al (2006) Transcriptional regulatory elements in the human genome. Annu Rev Genomics Hum Genet 7:29-59

15. Sabo PJ, Kuehn MS, Thurman R, Johnson BE, Johnson BE et al (2006) Genome-scale mapping of DNase I sensitivity in vivo using tiling DNA microarrays. Nat Methods 3:511-518

16. Brazda V, Laister RC, Jagelska EB, Arrowsmith C (2011) Cruciform structures are a common DNA feature important for regulating biological processes. BMC Mol Biol 12:33-48

17. Kendrick S, Hurley LH (2010) The role of G-quadruplex/i-motif secondary structures as cis-acting regulatory elements. Pure Appl Chem 82(8):1609-1621

18. Brooks TA, Hurley LH (2010) Targeting MYC Expression through G-Quadruplexes. Genes Cancer 1:641-649

19. Balasubramanian S, Hurley LH, Neidle S (2011) Targeting G-quadruplexes in gene promoters: a novel anticancer strategy? Nat Rev Drug Discov 10:261-275

20. Young SL, Korsmeyer SJ (1993) A negative regulatory element in the bcl-2 5'-untranslated region inhibits expression from an upstream promoter. Mol Cell Biol 13:3686-3697

21. Chen HM, Boxer LM (1995) P1 binding sites are negative regulators of bcl-2 expression in pre-B cells. Mol Cell Biol 15:3840-3847

22. Miyashita T, Harigai M, Hanada M, Reed JC (1994) Identification of a p53-dependent negative response element in the bcl-2 gene. Cancer Res 54:3131-3135

23. Duan H, Xiang H, Ma L, Boxer LM (2008) Functional Longrange Interactions of the $\mathrm{IgH} 3^{\prime}$ Enhancers with the bcl-2 Promoter Region in $t(14 ; 18)$ Lymphoma Cell. Oncogene 27:6720-6728

24. Siepi E, Lutz S, Meyer S, Panzner S (2011) An ion switch regulates fusion of charged membranes. Biophys J 100:2412-2421

25. Arranz A, Reinsch C, Papadakis KA, Dieckmann A, Rauchhaus U et al (2013) Treatment of experimental murine colitis with CD40 antisense oligonucleotides delivered in amphoteric liposomes. J Control Release 165:163-172

26. Andreakos E, Rauchhaus U, Stavropoulos A, Endert G, Wendisch $\mathrm{V}$ et al (2009) Amphoteric liposomes enable systemic antigenpresenting cell-directed delivery of CD40 antisense and are therapeutically effective in experimental arthritis. Arthritis Rheum 60:994-1005

27. Tolcher A, Rodrigueza WV, Rasco DW et al (2013) A Phase 1 Study of the BCL2 targeted deoxyribonucleic acid inhibitor (DNAi) PNT2258 in patients with advanced solid tumors. Cancer Chemother Pharmacol 2013 (in press)

28. Wagner A, Vorauer-Uhl K, Kreismayr G, Katinger H (2002) The crossflow injection technique-an improvement of the ethanol injection method. J Liposome Res 12(3):259-270

29. Wagner A, Vorauer-Uhl K, Katinger H (2002) Liposome produced in a pilot scale: production, purification and efficiency aspects. Eur J Pharm Biopharm 54:213-219

30. Corbett TH, Roberts BJ, Leopold WR, Peckman JC, Wilkoff LJ et al (1984) Induction and Chemotherapeutic Response of Two Transplantable Ductal Adenocarcinomas of the Pancreas in C57BL/6 Mice. Cancer Res 44:717-726

31. Mohammad RM, Mohamed AN, Smith MR, Jawadi N, AlKatib A (1993) A unique EBV- negative low-grade lymphoma 
line (WSU-FSCCL) exhibiting both $\mathrm{t}(14 ; 8)$ and $\mathrm{t}(8 ; 11)$. Cancer Genetics Cytogenetics 70:62-67

32. Dias N, Stein C (2002) Antisense oligonucleotides: basic concepts and mechanisms. Mol Cancer Ther 1:347-355

33. Kawasaki H, Taira K (2004) Induction of DNA methylation and gene silencing by short interfering RNAs in human cells. Nature 431:211-217

34. Rudin CM, Marshall JL, Huang CH, Kindler HL, Zhang C et al (2004) Delivery of a liposomal c-raf-1 antisense oligonucleotide by weekly bolus dosing in patients with advanced solid tumors: a phase I study. Clin Cancer Res 10:7244-7251

35. Fahy BN, Schlieman MG, Mortenson MM, Virudachalam S, Bold RJ (2005) Targeting BCL-2 overexpression in various human malignancies through NF-kappaB inhibition by the proteasome inhibitor bortezomib. Cancer Chemother Pharmacol 56:46-54

36. Gabizon A, Tzemach D, Mak L, Bronstein M, Horowitz AT (2002) Dose dependency of pharmacokinetics and therapeutic efficacy of pegylated liposomal doxorubicin (DOXIL) in Murine Models. J Drug Target 10:539-548

37. Sullivan GF, Amenta PS, Villanueva JD, Alvarez CJ, Yang JM, Hait WN (1998) The expression of drug resistance gene products during the progression of human prostate cancer. Clin Cancer Res 4:1393-1403

38. Janowski BA, Huffman KE, Schwartz JC, Ram R, Hardy D et al (2005) Inhibiting gene expression at transcription start sites in chromosomal DNA with antigene RNAs. Nat Chem Biol $1: 216-222$

39. Liu CM, Lui DP, Liang CC (2002) Oligonucleotide-mediated gene repair at DNA level: the potential applications for gene therapy. J Mol Med 80:620-628

40. Kole R, Krainer AR, Altman S (2012) RNA therapeutics: beyond RNA interference and antisense oligonucleotides. Nat Rev Drug Discovery 11:125-140

41. Vaishnaw AK, Gollob J, Gamba-Vitalo C, Hutabarat R, Sah D et al (2010) Review: status report on RNAi therapeutics. Silence $1: 14-26$
42. Deleavey GF, Damha MJ (2012) Designing chemically modified oligonucleotides for targeted gene silencing. Chem Biol 19:937-954

43. Chonn A, Cullis PR, Devine DV (1991) The role of surface charge in the activation of the classical and alternative pathways of complement by liposomes. J Immunol 146:4234-4241

44. Akinc A, Querbes W, De S, Qin J, Frank-Kamenetsky M et al (2010) Targeted Delivery of RNAi Therapeutics With Endogenous and Exogenous Ligand-Based Mechanisms. Mol Ther 18:1357-1364

45. Hope MJ, Rodrigueza WV (1995) Membrane lipids and model membrane systems. In: Severs N, Shotton D (eds) Rapid freezing, freeze fracture and deep etching (techniques in modern biomedical microscopy). Wiley, New York, pp 235-253

46. Rodrigueza WV, Pritchard PH, Hope MJ (1993) Influence of size and composition on the cholesterol mobilizing properties of liposomes in vivo. Biochim Biophys Acta 1153:9-19

47. Rodrigueza WV, Mazany KE, Essenburg AE, Pape ME, Bisgaier CL, Williams K (1997) Large versus small unilamellar vesicles mediate reverse cholesterol transport in vivo into two distinct hepatic metabolic pools: implications for the treatment of atherosclerosis. Arterioscler Thromb Vasc Biol 17:2132-2139

48. Farokhzad OC, Langer R (2009) Impact of nanotechnology on drug delivery. ACS Nano 3(1):16-20

49. Maurer N, Fenske DB, Cullis PR (2001) Developments in liposomal drug delivery systems. Expert Opin Biol Ther 1(6):923-947

50. Iqbal J, Meyer PN, Smith LM, Johnson NA, Vose JM et al (2011) BCL-2 Predicts Survival in Germinal Center B-cell-like DLBCL Treated with CHOP-like Therapy and Rituximab. Clin Cancer Res 17:7785-7795

51. Green TM, Young KH, Visco C, Xu-Monette ZY, Orazi A (2012) Immunohistochemical Double Hit Score is a Strong Predictor of Outcome in Patients with Diffuse Large B-Cell Lymphoma Treated with Rituximab Plus Cyclophsphamide, Doxorubicin, Vincristine, and Prednisone. J Clin Oncol 30:3460-3467 